\title{
BMJ Open Visibility of smoking among school- teachers in Spain and associations with student smoking: a cross-sectional study
}

José Julián Escario, ${ }^{1}$ Anna V Wilkinson ${ }^{2,3}$

To cite: Escario JJ, Wilkinson AV. Visibility of smoking among schoolteachers in Spain and associations with student smoking: a crosssectional study. BMJ Open 2018;8:e018736. doi:10.1136/ bmjopen-2017-018736

- Prepublication history for this paper is available online. To view these files, please visit the journal online (http://dx.doi. org/10.1136/bmjopen-2017018736).

Received 19 July 2017 Revised 20 November 2017 Accepted 24 November 2017

\section{(a) CrossMark}

${ }^{1}$ Faculty of Business and Public Management (Facultad de Empresa y Gestión Pública), University of Zaragoza, Huesca, Spain

${ }^{2}$ School of Public Health, The University of Texas Health Science Center at Houston, Houston, Texas, USA ${ }^{3}$ Division of Epidemiology, Human Genetics and Environmental Sciences, Michael \& Susan Dell Center for Healthy Living, Austin, Texas, USA

Correspondence to Dr José Julián Escario; jescario@unizar.es

\section{ABSTRACT}

Objective Limited research has examined the association between smoking among schoolteachers and student smoking. This paper seeks to assess whether smoking visibility on school grounds among schoolteachers is associated with student smoking. We examine both smoking behaviour and the number of cigarettes consumed.

Methods We use a school-based cross-sectional survey carried out by the Spanish Government's Delegation for the National Plan on Drugs. A total of 27503 students between 14 and 18 years of age completed an anonymous survey in 2013. Count data regressions were used to assess the association between observed teacher smoking and adolescent smoking behaviour.

Results High levels of visibility of teacher smoking on school grounds increased the odds of being a smoker among students $(\mathrm{OR}=2.09$ and $\mathrm{OR}=1.64$, for the highest levels of visibility), but the impact on the quantity of cigarettes smoked, although positive, was not significant. Conclusion Teacher smoking on school grounds is associated with student smoking behaviour. Consequently, smoking policies designed to prevent adolescent smoking should address this important social environment.

\section{INTRODUCTION AND BACKGROUND}

Non-communicable diseases (primarily cancers, diabetes, cardiovascular disease and chronic lung diseases) are directly responsible for more than 36 million deaths a year worldwide. Given that tobacco is the largest preventable risk factor for non-communicable diseases, addressing tobacco is of paramount importance to reduce premature deaths. $^{12}$

Tobacco use clearly remains a major public health issue, and identifying risk factors associated with smoking uptake is critically important. ${ }^{3}$ A wide range of risk factors have been identified that include individual characteristics, socioeconomic status, price, taxes, media and advertising exposure, lack of social support, peer and family influences, among others. ${ }^{4}$ Most research examining the uptake
Strengths and limitations of this study

Both the decision to smoke or not and the number of cigarettes consumed are jointly considered using a large nationally representative sample size of 27503 participants.

- The analyses expanded the traditional dichotomous measure of exposure to observing teacher smoking on school grounds and used a five-level categorical measure to take into account different levels of exposure. This paper analyses if the significance and the intensity of the association between student smoking and perceived teacher smoking depends on the level of the latter.

- Results may not generalise to other countries.

of smoking has focused on adolescents, as preventing adolescents from smoking is one of the most cost-efficient approaches to reducing the uptake of smoking. ${ }^{5}$ Moreover, thousands of adolescents try smoking every day, a proportion of whom will become addicted adult smokers. ${ }^{6}$

Apart from addiction, another factor that could reduce the effectiveness of interventions designed to reduce smoking among adolescents is smoking among social environment of the adolescents; this includes teacher smoking. ${ }^{4}$ Although Spain is among the countries with the highest level of achievement in smoke-free legislation, ${ }^{2}$ in 2014 , $9.2 \%$ of teachers reported that they had seen other teachers smoking on school grounds. ${ }^{8}$

The Social Ecological Model highlights the importance of the social environment as a multidimensional and complex determinant of health behaviour. ${ }^{9}$ Given that adolescents spend much of their time at school, teachers may exert an important influence, as they interact with students almost every day. Accordingly, teachers serve as role models and opinion leaders for youth. Yet despite the importance of this social environmental 
factor, few studies have investigated the effects of teacher smoking behaviour on adolescent smoking. ${ }^{10}$

Moreover, some previous studies conducted in a variety of countries report a positive association between exposure to teacher smoking on school grounds and student smoking behaviour. ${ }^{3} 4711$ Taking all these facts into account, we propose the following two hypotheses:

H1a: Higher levels of exposure to teacher smoking are associated with student smoking.

H1b: Higher levels of exposure to teacher smoking are associated with increased quantity of cigarettes smoked.

However, the results from previous studies have been inconclusive. Thus, others studies have not found a positive association between awareness of teacher smoking and student smoking, ${ }^{12}$ while others have pointed to a more nuanced relationship. For example, Piontek et $\mathrm{al}^{13}$ reported a positive association between the presence of teachers smoking on school grounds and smoking behaviour for older students but not younger students. Similarly, others have argued that higher perceived teacher smoking was associated with student smoking among girls only. ${ }^{4}$ Consequently, more research is necessary to clarify these relationships. Reviewing these results, it is possible that the significance and the intensity of the association between student smoking and perceived teacher smoking depends on the level of the latter. In other words, we propose the following hypothesis:

H2: There is heterogeneity in the association between teacher smoking and student smoking.

The Social Ecological Model also justifies the consideration of parents and friends as important aspects of the adolescents' social environment. Indeed, previous studies suggest that the number of peers and parents that smoke is strongly associated with adolescent smoking. ${ }^{11} 14-18$ Taking these facts into account, we propose:

H3: Having friends who smoke will be positively associated with self-reported smoking.

H4: Having parents who smoke will be positively associated with self-reported smoking.

In this way, our main purpose is to examine the extent to which student smoking is associated with the smoking behaviour of key players in their social environment, specifically that of teachers, and also of best friends and parents, after adjusting for several socioeconomic variables. Here, we seek to contribute to the literature by expanding the traditional dichotomous measure of exposure to observing teacher smoking on school grounds. While a few studies have used a three-level measure, ${ }^{411}$ we use a five-level categorical measure to take into account different levels of exposure. Finally, there is a dearth of empirical research on exposure to teachers' smoking and the number of cigarettes smoked. As an exception, Nikaj and Chaloupka reported that teacher and personnel smoking on school grounds is associated with higher smoking prevalence and higher cigarette consumption among females. ${ }^{7}$ In this respect, this study contributes to this scarce literature by considering teachers' smoking as a predictor not only on the probability of student smoking but also on the quantity smoked.

\section{METHODS}

\section{Participants}

The data we use are drawn from the 2012 Spanish Survey on Drug Use in the School Population. This survey, with 27503 students, constitutes a representative sample of the Spanish school population between the age of 14 and 18 years. The survey, which uses established validated measures, ${ }^{19}{ }^{20}$ has the ethical approval of the Spanish Government's Delegation for the National Plan on Drugs, a government organisation that works as a partner of the European Monitoring Centre for Drugs and Drug Addiction. The 2012 Survey on Drug Use in the School Population was conducted between February 14 and April 30 in 2013. Students completed an anonymous self-administered questionnaire during a 45 to $60 \mathrm{~min}$ class period. The survey follows a two-stage cluster sampling design in which schools (primary units) and classes (secondary units) have been sequentially selected in a random way. The majority, $86.5 \%$ of the selected schools participated in the survey, resulting in 747 schools and 1523 classes. Once a class was selected, all students enrolled in the class were included in the survey. The sampling error is $0.6 \%$ at the $95 \%$ CI.

\section{Dependent variable}

Our dependent variable measures daily smoking among current smokers and is based on the following question: "How many cigarettes do you smoke daily?" Response options included: "I haven't smoked cigarettes in my life"; "I don't smoke daily" or the number of cigarettes smoked per day. For the dependent variable, smoking consumption, students who selected the two first options were coded as zero cigarettes per day, and for students who reported daily smoking, the self-reported value was used.

\section{Main exposures of interest}

The primary exposure of interest is visibility of teacher smoking, for which we use answers to the question: "How frequently have you seen teachers smoke tobacco on school grounds (including school buildings and outdoors on the school premises) in the last 30 days?". Response options included: 'every day or almost every day'; 'more than half of the days'; 'approximately half of the days'; 'less than half of the days' and 'no days'. We computed four dichotomous variables using the four first options: every day or almost every day (daily), more than half of the days (most days), approximately half of the days (half of the days) and less than half of the days (less than half days), with the fifth response option 'no days' serving as the reference category (never). Of note, we cannot separate the visibility of teacher smoking inside the school building from teacher smoking outdoors on the school premises. ${ }^{11}$

The smoking behaviour of peers and cohabitant parents, secondary exposures of interest, was also assessed. The variable 'friends smoke' is a dichotomous variable $(1=$ yes, $0=$ no $)$, indicating whether or not some of the closest friends smoke. In addition, two dichotomous variables examined the smoking status of cohabitant 
parents, mother smokes and father smokes $(1=$ smoker, $0=$ non-smoker).

\section{Covariates}

Two variables that assess school characteristics are included. The first one, school type ( $1=$ public, $0=$ private $)$, controlled for the type of school. The second called school Programme indicated whether or not the school had implemented a school-based tobacco and other drug use prevention programme ( $1=$ yes, $0=$ no) .

Other covariates included: male ( $1=$ boy, $0=$ girl), age 15 to age 18 ( 4 dichotomous variables for ages 15 to 18 , age 14 is the reference category), immigrant ( $1=y e s, 0=$ native), income (disposable money weekly in euros by the adolescent), working mother and working father (1=working, $0=$ otherwise), retired mother and retired father $(1=$ retired, $0=$ otherwise), and finally, two binary variables that indicate whether or not the adolescent has a bad relationship with his/her mother and with his/her father, bad relations mother and bad relations father $(1=y e s, 0=n o)$.

\section{Data analysis}

Given the non-negative integer nature of the dependent variables and the high, from a statistical point of view, proportion of zero responses, we used count data models specifically developed to deal with high proportions of zeros, commonly referred to as zero inflated models. ${ }^{21}$ More concretely, we considered the zero inflated Poisson model and the zero inflated negative binomial model (ZINB). The first is nested in the second, and a likelihood ratio test can be used to discriminate between both models. The result of this test selects the ZINB model as our preferred model. This model combines two processes. The first is governed by a binary distribution (a logistic process). The second process follows a negative binomial distribution. In this model, both processes are jointly estimated by maximum likelihood.

Given that the conditional mean is not linear in count data models, it is not easy to interpret the coefficients directly. Instead, the ORs and the incidence rate ratios (IRRs) are reported. The OR yields the relative amount by which the odd of the outcome (being a smoker) increases or decreases, depending on whether the OR is greater or less than 1.0, when the independent variable increases by one unit. By the same token, the IRR provides the relative change in the level of cigarette consumption when the independent variable increases by one unit. Similar to the OR, an IRR higher or lower than one implies a positive or negative association, respectively, between the explanatory variable and the number of cigarettes smoked. All the analyses were carried out with Stata V.8 software and all covariates were jointly introduced in the estimated models.

\section{RESULTS}

Results from the descriptive analysis are displayed in table 1. Overall, $16.6 \%$ of the students reported daily smoking in the past month. Smoking was more prevalent
Table 1 Descriptive analysis

\begin{tabular}{|c|c|c|c|}
\hline & All & Boys & Girls \\
\hline $\begin{array}{l}\text { Smoking prevalence* } \mathrm{P} \\
\text { value }<0.0001\end{array}$ & 16.6 & 15.4 & 17.9 \\
\hline $\begin{array}{l}\text { Smoking consumption }{ }^{*} P \\
\text { value }=0.1780\end{array}$ & 1.150 & 1.130 & 1.170 \\
\hline $\begin{array}{l}\text { Smoking consumption }>0 * \\
P \text { value }=0.0002\end{array}$ & 6.360 & 6.390 & 6.099 \\
\hline \multicolumn{4}{|l|}{ Visibility teacher smoking } \\
\hline Daily & 23.5 & 26.1 & 20.9 \\
\hline Most days & 8.8 & 9.3 & 8.3 \\
\hline Half of the days & 7.3 & 6.8 & 7.8 \\
\hline Less than half days & 14.4 & 14.0 & 14.9 \\
\hline Never & 46.0 & 43.8 & 48.2 \\
\hline Friends smoke & 78.1 & 79.8 & 76.5 \\
\hline Mother smokes & 32.1 & 31.3 & 33.0 \\
\hline Father smokes & 32.8 & 32.4 & 33.1 \\
\hline School type (public) & 69.8 & 70.1 & 69.6 \\
\hline School programme & 75.9 & 76.2 & 75.6 \\
\hline Male & 50.5 & 100.0 & 0.0 \\
\hline Age 14 & 13.5 & 13.6 & 13.5 \\
\hline Age 15 & 20.7 & 20.2 & 21.2 \\
\hline Age 16 & 24.0 & 23.2 & 24.8 \\
\hline Age 17 & 26.4 & 27.0 & 25.8 \\
\hline Age 18 & 15.3 & 16.0 & 14.7 \\
\hline Immigrant & 11.4 & 11.2 & 11.5 \\
\hline Income & $€ 16.5$ & $€ 18.0$ & $€ 14.9$ \\
\hline Working mother & 59.4 & 59.7 & 59.2 \\
\hline Working father & 76.4 & 77.6 & 75.1 \\
\hline Retired mother & 1.4 & 1.3 & 1.5 \\
\hline Retired father & 4.1 & 3.8 & 4.4 \\
\hline Bad relations mother & 2.4 & 2.1 & 2.8 \\
\hline Bad relations father & 5.3 & 4.3 & 6.3 \\
\hline
\end{tabular}

Sampling weights have been taken into account with the 'svyset and svy' commands. All figures indicate percentages except for smoking consumption and income.

${ }^{*}$ A two-sample t-test with unequal variances for the null hypothesis of equal mean among genders.

among girls $(17.9 \%)$ than boys $(15.4 \%)$, and the difference is significant. Consequently, the prevalence of non-smokers is $83.4 \%$. In contrast, among smokers, boys smoke more cigarettes (6.39) than girls (6.10) on average. Almost half $(46 \%)$ of the adolescents reported they had not noticed teacher smoking, while $23.5 \%$ reported noticing teacher smoking on school grounds every day.

Of note, $76.5 \%$ of the girls and $79.8 \%$ of the boys reported that some of their closest friends smoke. The prevalence of parental smoking was similar for fathers and mothers, with rates of $32.8 \%$ and $32.1 \%$, respectively.

The fully adjusted estimates from the Zero Inflated Negative Binomial model are displayed in tables 2 and 3. 


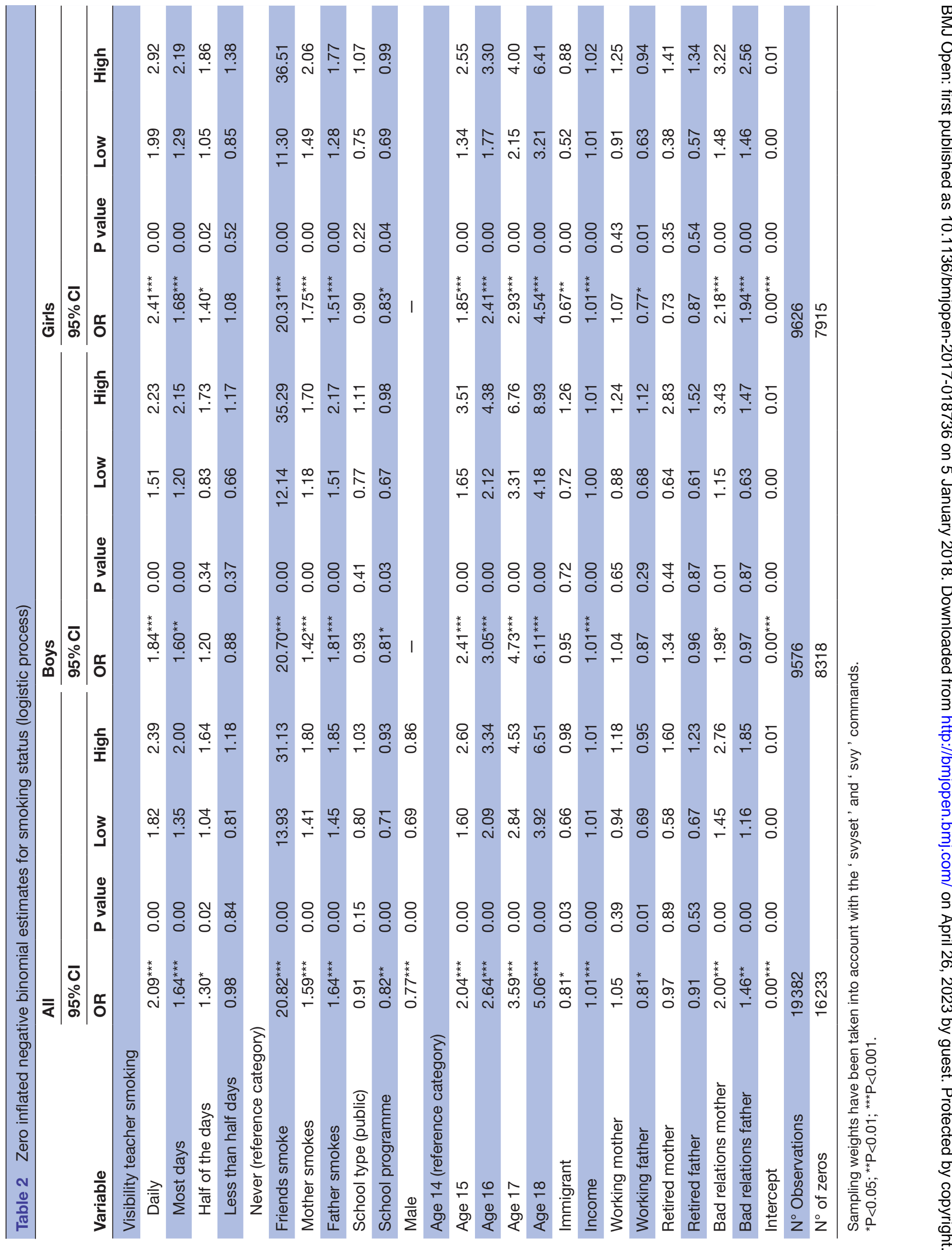




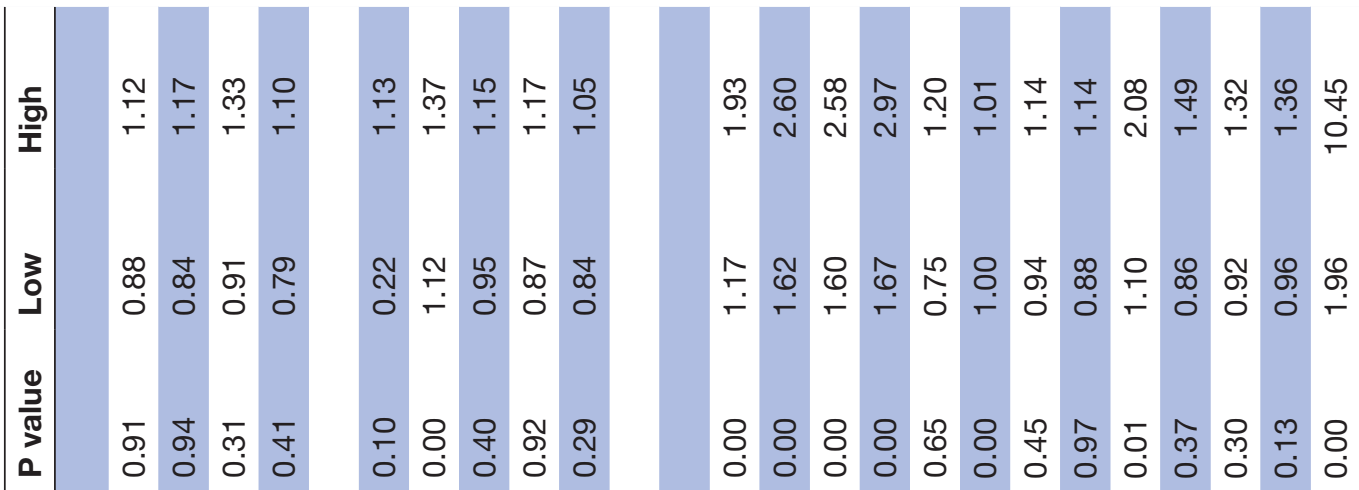

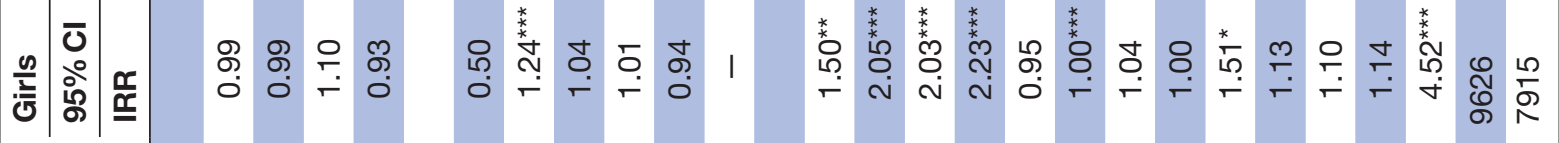

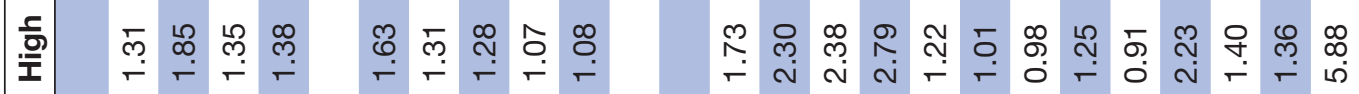

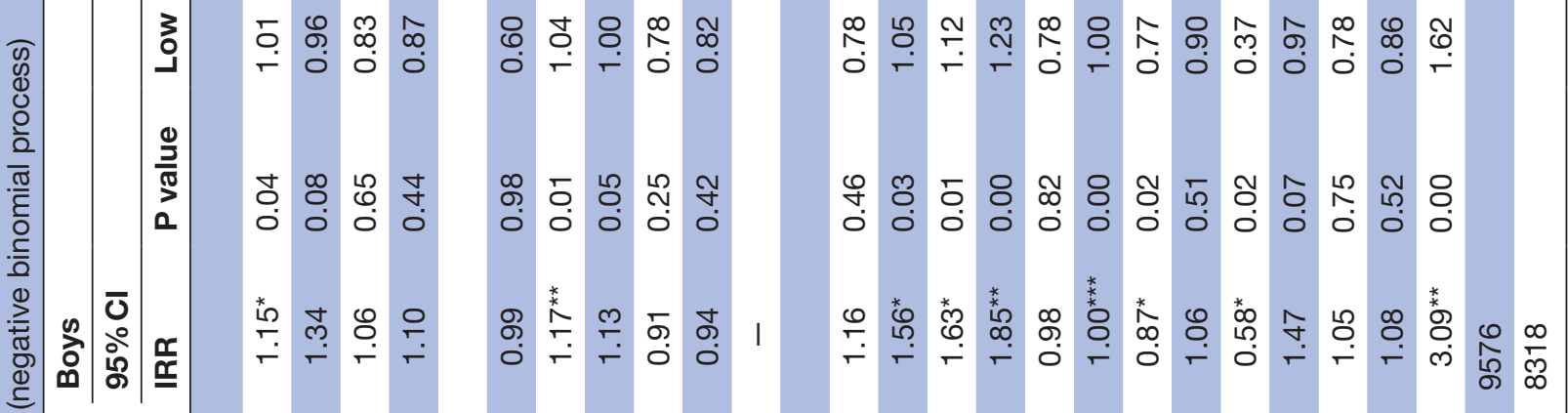

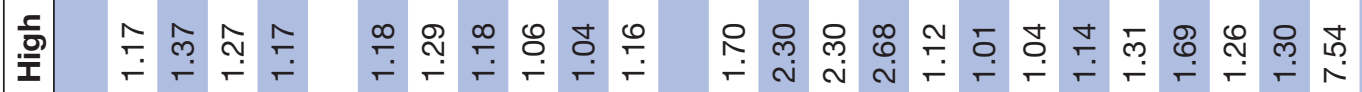

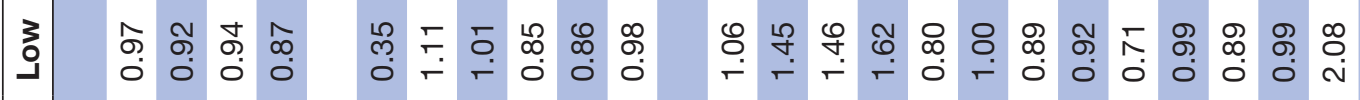

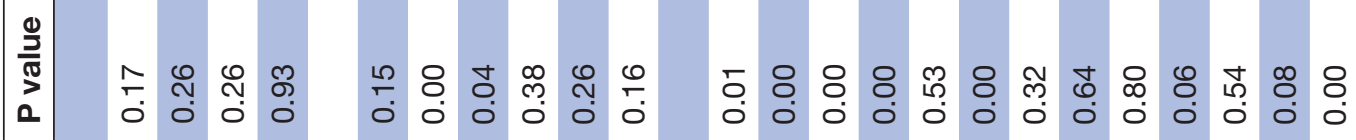

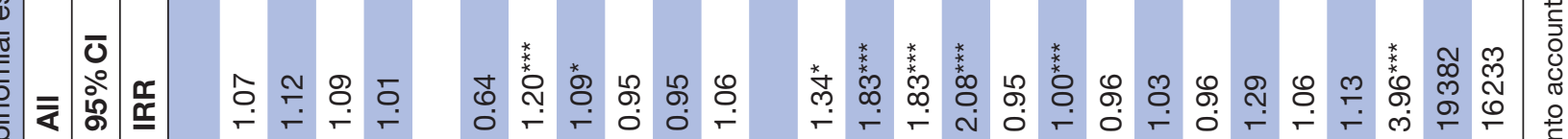

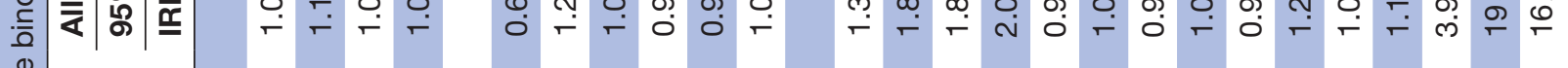

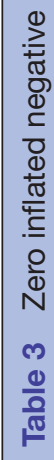
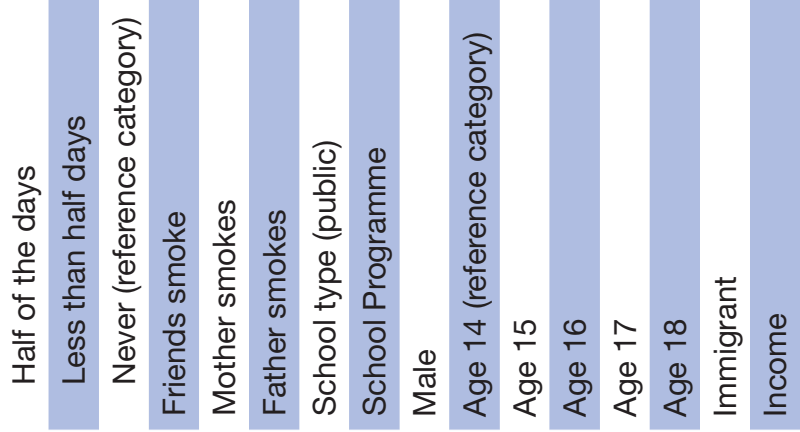

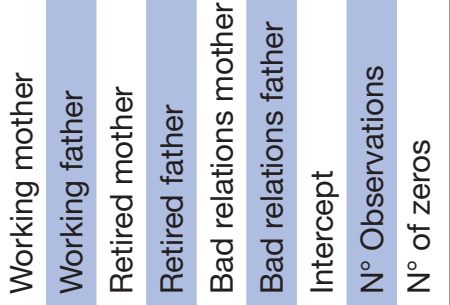


Table 2 reports associations between the covariates and being a smoker, while table 3 reports associations of the same covariates with the number of cigarettes smoked; both analyses control for all the other variables in the model. We focus on the estimates for teacher, friend and parent smoking rather than the estimates for the socioeconomic characteristics, which can be found in the tables.

Two points are worth emphasising with regards to observed teacher smoking. First, teacher smoking on school grounds is associated with an increase in the odds of being a smoker. The odds of being a smoker increase as the reported visibility of teacher smoking increases $\left(\mathrm{OR}_{\text {Half Davs }}=1.30,95 \%\right.$ CI 1.04 to $1.64 ; \mathrm{OR}_{\text {Most Davs }}=1.64$, $95 \%$ CI 1.35 to 2.00 and $\mathrm{OR}_{\text {Daily }}=2.09,95 \%$ CI 1.82 to 2.39 ). These estimates provide support for H1a. With regard to $\mathrm{H} 1 \mathrm{~b}$, as the visibility of teacher smoking increases, the quantity of cigarettes smoked also increases, although this association is not significant. Here, we conclude that the association between teacher smoking and student smoking depends on the level of teacher smoking visibility, which provides evidence in support of $\mathrm{H} 2$.

In our analysis, having friends who smoke appears to be the strongest predictor of daily smoking $(\mathrm{OR}=20.82$, 95\% CI 13.93 to 31.13 ), as having close friends who are smokers greatly increases the odds of being a smoker. This result supports H3. However, having close friends who smoke was not associated with the number of cigarettes smoked. Second, parent smoking also increases the odds of being a smoker (OR=1.59, 95\% CI 1.41 to 1.80 for mother smoking and $\mathrm{OR}=1.64,95 \%$ CI 1.45 to 1.85 for father smoking). Moreover, parents' smoking is also associated with the number of cigarettes smoked, thus, mothers' smoking increases the number of cigarettes smoked by around $20 \%$ (IRR $=1.20,95 \%$ CI 1.11 to 1.29 ) and fathers' smoking by around $9 \%$ (IRR $=1.09,95 \%$ CI 1.01 to 1.18 ). These findings support $\mathrm{H} 4$.

These associations are quite robust for both genders. Reporting exposure to teacher smoking on daily $\left(\mathrm{OR}_{\text {Daily }}\right)$ or most days $\left(\mathrm{OR}_{\text {Most Days }}\right)$ remained significant for both boys and girls. However, teacher smoking appears to be a stronger predictor on girls daily smoking than on boys daily smoking, as reporting exposure to seeing their teachers smoke on half of the last 30 days also remained significant for girls (OR=1.40, 95\% CI 1.05 to 1.86 ) but not boys (OR=1.20, 95\% CI 0.83 to 1.73$)$. Of note, the associations between having a close friend who is a smoker were almost identical for boys and girls, with ORs around 20.

While the odds associated with mothers' smoking and fathers' smoking were on the whole of similar magnitude (1.59 and 1.64, respectively), we found differences across genders. Although the odds of being a smoker increased for both sexes with both parents' smoking, the association is stronger for the same gender dyads than between gender dyads. In the case of boys, the odds of being a smoker are higher for father smoking $(\mathrm{OR}=1.81,95 \% \mathrm{CI}$ 1.51 to 2.17$)$ than for mother smoking $(\mathrm{OR}=1.42,95 \% \mathrm{CI}$
1.18 to 1.70 ). For girls, we observe the opposite, although the difference is not significant-the odds of being a smoker are higher for mother smoking $(\mathrm{OR}=1.75,95 \% \mathrm{CI}$ 1.49 to 2.06) than for father smoking ( $\mathrm{OR}=1.51,95 \%$ CI 1.28 to 1.77$)$.

\section{DISCUSSION}

Our results suggest that teacher smoking (H1a, H2), friend smoking (H3) and parent smoking (H4) are important predictors of adolescents' decisions to smoke or not. Moreover, parent smoking is also associated with the number of cigarettes smoked by adolescents. Thus, our results are consistent with our hypotheses and, consequently, with the Social Ecological Model ${ }^{9}$ that postulates the important role of the social environment in shaping health decisions.

The literature is not conclusive about the relationship between exposure to teacher smoking on school grounds and student smoking behaviour. Some authors reported no association with either ever or current smoking, ${ }^{12}$ while others report a positive association with ever smoking but not with current smoking. ${ }^{14}$ Others have found evidence for a positive association between teachers smoking on school grounds and adolescent smoking for older students but not for younger students ${ }^{13}$ and for genderbased effect (ie, girls but not boys). ${ }^{4}$

Our results, which suggest that the association between student smoking and teacher smoking depends on the level of the exposure to teacher smoking (H2), help to explain these divergent results across studies. Specifically, by examining five different levels of exposure, we found no relationship between student smoking behaviour and visibility of teacher smoking on school grounds at the lowest level of exposure for either girls or boys and only among girls when the exposure is present roughly $50 \%$ of the time. However, this risk was clearly significant when students noticed that teachers smoke almost daily or daily. Consequently, the different levels of exposure across surveys from different countries, when collapsed into a dichotomous variable, could yield non-significant or significant effects, depending on exposure levels in different countries. In support of our argument, there is evidence that the smoking prevalence among teachers differs enormously between countries.

Several mechanisms may explain this association between teacher smoking and student smoking. First, according to the Social Ecological Model ${ }^{9}$ and Social Learning Theory, ${ }^{22}$ students imitate teacher behaviour as teachers can be considered adult role models and opinion leaders. While the data we examined are cross-sectional in nature, prohibiting the establishment of causality, the theories underscore the possibility that a part of this association could reflect a causal effect, through role modelling. Alternatively, the association could simply reflect the fact that students who smoke are more prone to see teachers smoke. Second, when teachers smoke on school grounds, it underscores the 
idea that school tobacco policies are not restrictive ${ }^{12}$ and, consequently, may diminish the perceived severity of punishment associated with violating the policy. ${ }^{23}$ It is difficult to enforce tobacco-free school rules if they are not clearly promoted and communicated. ${ }^{5}$ Observing smoking among teachers may serve to undermine the school administration's authority and perceived legitimacy to promote and enforce such rules and foster norms among students to ignore or rebel against these rules. ${ }^{13}$ In addition, some evidence underscores the importance of enforcing policies as students are often unaware of tobacco rules at school and associated punishments. ${ }^{24}$ Thus students who observe teacher smoking could think there are no rules or that the existing rules are more permissive than they actually are.

It is important to note that the magnitude of the association between teacher smoking and student smoking is higher, similar or lower to that of parent smoking and child smoking, depending on the level of teacher smoking visibility. Observing teachers smoke every day, or almost every day, on school grounds shows a higher magnitude of association with adolescent smoking behaviour than having a parent who smokes. The magnitude of the association is similar when students observe teacher smoking on more than half of the days, and it is lower when students observe teacher smoke approximately half of the days. However, the strength of the association between having close friends who smoke and adolescent smoking is stronger than for either teachers or parents. Indeed, having close friends who smoke is one of the most consistent predictors of adolescent smoking, ${ }^{25}$ however, some authors caution that this correlation can be overestimated. ${ }^{26} 27$ Others have found ORs of two digits. ${ }^{11}$ They justify this by two hypotheses: smokers tend to spend time with other smokers (selection hypothesis), and smokers are more aware of other smokers (projection hypothesis).

Although parent, friend and teacher smoking behaviour all are positively associated with the probability of student smoking, only parent smoking is a significant predictor of the quantity of cigarettes. This is primarily true for mothers who smoke. ${ }^{1528-30}$ This may reflect that for most adolescents, it is easier to obtain cigarettes free of charge from their parents at home by taking them directly than from their teachers or friends. This reasoning is plausible with the result that smokers are restricted by their economic budget. In this way, our estimates show that disposable income appears as a significant variable for both the decision to smoke or not and the number of cigarettes smoked. ${ }^{15}$

It is interesting to note that we found several gender patterns of social interaction. ${ }^{31}$ Starting with the effects in the first equation, we found that teacher smoking follows the hypothesis of equivalent socialisation, as the ORs are quite similar on boys and girls, although slightly stronger among girls. The same equivalent socialisation hypothesis is found for friends, as ORs are almost identical for both sexes. In contrast, parent smoking shows more pronounced gender specific socialisation, where the highest socialisation is found across same-sex dyads. Finally, when focusing on the level of smoking, we found that the mother is the dominant predictor.

All in all, our results suggest that exposure to teacher smoking on school premises is associated with student smoking, and in particular, when students notice teachers smoking on school grounds on most or all days. Our results show that $54 \%$ of students noticed teacher smoking on school grounds. This might reflect low enforcement of current smoking restrictions on school grounds in Spain, which prohibited any smoking in school buildings and outdoor on school premises, and underscores the need to enforce the current tobacco-free school polices. Encouraging teachers to refrain from smoking on school grounds is important, as they serve as role models and their smoking on school premises could serve to undermine and weaken tobacco-free policies. Consequently, state and school campaigns could include teachers as special targets, to both raise awareness about the association between their smoking and student behaviour, as well as assist with cessation.

Our results provide evidence that tobacco prevention policies should address the different social contexts that influence smoking prevalence and consumption. Tobacco prevention programme and policies are important to have in place in schools, but need to extend beyond schools by targeting parents as well, as parents and teachers, share an important and roughly equal role on adolescent smoking behaviour. Developing school programme that encourage parents to quit smoking could be an effective approach to reducing the smoking prevalence, as well as the number of cigarettes smoked, among adolescents. A recent review article provides evidence that schoolbased and family-based programme are effective in reducing smoking. ${ }^{32}$ Of note, including parents as targets of these school programme will not have significant budgetary impacts and could serve to reduce smoking initiation among adolescent students via intergenerational transmissions. ${ }^{15} 30$

Of importance, having close friends who smoke has a stronger association with adolescent smoking than either parent or teacher smoking. Peer effects may function as 'social multipliers' that could serve to amplify the effects of policy interventions. ${ }^{162733}$ Effective school policies will lead to the overall reduction in the number of smokers at the individual level. This reduction in the prevalence of smokers will also have an indirect effect, as students/adolescents will have fewer friends who smoke and, consequently, will experience decreased social pressure to smoke.

The paper presents several limitations. First, we use cross-sectional data, which do not permit us to infer causality and to control for unobserved heterogeneity as longitudinal data afford. Second, results may 
not generalise to other countries. Moreover, given the self-reported data, under-reporting could lead to some measurement error. However, this concern is mitigated as self-reports yield reliable estimates of substance use when data are gathered confidentially. ${ }^{34}$ In addition, the survey data lack information about how tobacco school policies are designed and implemented at each school. Yet despite these limitations, our results are plausible and have implications for policy.

Contributors JJE carried out the statistical analyses. JJE and AVW drafted and revised the manuscript critically for important intellectual content. All authors read and approved the manuscript.

Competing interests None declared.

Provenance and peer review Not commissioned; externally peer reviewed.

Data sharing statement Data are available from Spanish Government's Delegation for the National Plan on Drugs. Syntax to reproduce the results presented here is available from the corresponding author on request.

Open Access This is an Open Access article distributed in accordance with the Creative Commons Attribution Non Commercial (CC BY-NC 4.0) license, which permits others to distribute, remix, adapt, build upon this work non-commercially, and license their derivative works on different terms, provided the original work is properly cited and the use is non-commercial. See: http://creativecommons.org/ licenses/by-nc/4.0/

(c) Article author(s) (or their employer(s) unless otherwise stated in the text of the article) 2018. All rights reserved. No commercial use is permitted unless otherwise expressly granted.

\section{REFERENCES}

1. World Health Organization. WHO report on the global tobacco epidemic, 2013: enforcing bans on tobacco advertising, promotion and sponsorship. Luxembourg: World Health Organization, 2013.

2. World Health Organization. WHO report on the global tobacco epidemic, 2015: raising taxes on tobacco. Luxembourg: World Health Organization, 2015.

3. Zhang X, Li Y, Zhang Q, et al. Smoking and its risk factors in Chinese elementary and middle school students: a nationally representative sample study. Addict Behav 2014;39:837-41.

4. Roohafza H, Heidari K, Omidi R, et al. Adolescent perception on school environment and smoking behavior: analysis of isfahan tobacco use prevention program. Int J Prev Med 2014;5:S139-45.

5. Paek HJ, Hove T, Oh HJ. Multilevel analysis of the impact of schoollevel tobacco policies on adolescent smoking: the case of Michigan. $J$ Sch Health 2013;83:679-89.

6. Prochaska JO, DiClemente CC, Norcross JC. In search of how people change. Applications to addictive behaviors. Am Psychol 1992;47:1102-14.

7. Nikaj S, Chaloupka F. School personnel smoking, school-level policies, and adolescent smoking in low- and middle-income countries. Tob Control 2016;25:664-70.

8. Spanish Government's Delegation for the National Plan on Drugs. Spanish survey on drugs and other addictions among compulsory secondary education's teachers. 2016 http://www.pnsd.msssi.gob. es/profesionales/sistemasInformacion/sistemalnformacion/pdf/2016 EPAD_Encuesta_Prof_Ens_Sec_datos_2014.pdf (accessed Oct 2017).

9. Stokols D. Establishing and maintaining healthy environments. Toward a social ecology of health promotion. Am Psychol 1992;47:6-22.

10. Erick PN, Smith DR. Prevalence of tobacco smoking among school teachers in Botswana. Tob Induc Dis 2013;11:24.
11. Poulsen LH, Osler M, Roberts C, et al. Exposure to teachers smoking and adolescent smoking behaviour: analysis of cross sectional data from Denmark. Tob Control 2002;11:246-51.

12. Huang HW, Lu CC, Yang YH, et al. Smoking behaviours of adolescents, influenced by smoking of teachers, family and friends. Int Nurs Rev 2014;61:220-7.

13. Piontek D, Buehler A, Rudolph U, et al. Social contexts in adolescent smoking: does school policy matter? Health Educ Res 2008;23:1029-38.

14. El-Amin S-T, Nwaru BI, Ginawi I, et al. The role of parents, friends and teachers in adolescents' cigarette smoking and tombak dipping in Sudan. Tob Control 2011;20:94-9.

15. Escario JJ, Wilkinson AV. The intergenerational transmission of smoking across three cohabitant generations: a count data approach. J Community Health 2015;40:912-9.

16. Lundborg P. Having the wrong friends? Peer effects in adolescent substance use. J Health Econ 2006;25:214-33.

17. Sabiston CM, Lovato CY, Ahmed R, et al. School smoking policy characteristics and individual perceptions of the school tobacco context: are they linked to students' smoking status? J Youth Adolesc 2009;38:1374-87.

18. Borderías L, Duarte R, Escario JJ, et al. Addiction and other reasons adolescent smokers give to justify smoking. Subst Use Misuse 2015;50:1552-9.

19. European Monitoring Centre for Drugs and Drug Addiction (2016). ESPAD report 2015: results from the european school survey project on alcohol and other drugs. http://www.espad.org/sites/espad.org/ files/ESPAD_report_2015.pdf (accessed Oct 2017).

20. Hibell B, Bjarnason T. Report from the ESPAD 07. swedish council for information on alcohol and other drugs. Stockholm, 2008. http:// www.espad.org/sites/espad.org/files/The_2007_ESPAD_ReportFULL_091006.pdf (accessed Oct 2017).

21. Cameron AC, Trivedi PK. Regression analysis of count data. USA: Cambridge University Press, 2013:1-567.

22. Bandura A. Social learning theory. Englewood Cliffs, NJ: Prentice Hall, 1977.

23. Lovato CY, Sabiston CM, Hadd V, et al. The impact of school smoking policies and student perceptions of enforcement on school smoking prevalence and location of smoking. Health Educ Res 2007;22:782-93.

24. Noland M, Rayens MK, Riggs RS, et al. Student and principal perceptions of school tobacco policy. Am J Health Educ 2011;42:41-9.

25. Kobus K. Peers and adolescent smoking. Addiction 2003;98(Suppl 1):37-55.

26. Foster G. It's not your peers, and it's not your friends: some progress toward understanding the educational peer effect mechanism. J Public Econ 2006;90:1455-75.

27. Duarte R, Escario JJ, Molina JA. Are estimated peer effects on smoking robust? Evidence from adolescent students in Spain. Empir Econ 2014;46:1167-79.

28. Duarte R, Escario JJ, Molina JA. Smoking transmission in-home across three generations. J Subst Use 2016;21:268-72.

29. El-Amin SE, Kinnunen JM, Ollila H, et al. Transmission of smoking across three generations in Finland. Int J Environ Res Public Health 2015;13:74.

30. Vandewater EA, Park SE, Carey FR, et al. Intergenerational transfer of smoking across three generations and forty-five years. Nicotine Tob Res 2014;16:11-17.

31. Kulik L. Like-sex versus opposite-sex effects in transmission of gender role ideology from parents to adolescents in Israel. $J$ Youth Adolesc 2002;31:451-7.

32. Das JK, Salam RA, Arshad A, et al. Interventions for adolescent substance abuse: an overview of systematic reviews. J Adolesc Health 2016;59:S61-75.

33. Ali MM, Dwyer DS. Estimating peer effects in sexual behavior among adolescents. J Adolesc 2011;34:183-90.

34. Dolcini MM, Adler NE, Ginsberg D. Factors influencing agreement between self-reports and biological measures of smoking among adolescents. J Res Adolesc 1996;6:515-42. 